\title{
MODEL PENGEMBANGAN PERIKANAN TANGKAP BERBASIS MINAPOLITAN DI KABUPATEN GORONTALO UTARA
}

\author{
(MODEL OF CAPTURE FISHERIES DEVELOPMENT BASED ON \\ MINAPOLITAN CONCEPT IN NORTH GORONTALO DISTRICT)
}

\author{
Alfi Sahri R Baruadi'2, Domu Simbolon ${ }^{3}$, Ari Purbayanto ${ }^{3}$, Roza Yusfiandayani ${ }^{3}$ \\ ${ }^{1}$ Corresponding author \\ ${ }^{2}$ Jurusan Perikanan Fakultas Ilmu-ilmu Pertanian, \\ Universitas Negeri Gorontalo, E-mail : alfisahri.ung@gmail.com \\ ${ }^{3}$ Departemen Pemanfaatan Sumberdaya Perikanan \\ Fakultas Perikanan dan Ilmu Kelautan, IPB
}

\begin{abstract}
Fishery resources at NorbGorontalo disrict was huge. The potential of Fishery Management Area from Laut Sulawesi to Pasicific Ocean includes around 590.970 ton of pelagicdivided into175.260 ton large pelagic, 384.750 ton small pelagic and the other kind of fish around 30.960 ton. On the other hand, the utilization of fishery resources still minimun that was only 46\%. Government at North Gorontalo made capture fisheris as a main program to improve society welfare to minimize the lack of fishery resources utilization. The government should be aware of this situation to formulate and decide each policy. Policy that has been applied in this recent year in NorthGorontalo district was Minapolitan and it was held by the Indonesia Ministry of Marine and Fishery joined with Local Government. So, research of development fishery capture based minapolitan model was needed to designed a policy model as a guide to decide a capture fisheries policy. Methodology that using in this research was surplus production analysis to analyze the fish resource, proper tools to capture fish analysis, and SEM (Structure Equation Modeling) analysis. The result of this research showed that the utilization of fishery resources still lack under MSY (Maximum Sustainable Yield). Some of programs that should be developed were purse seine, hand line tuna,liftnet, hand line, and payang. The objective of minapolitan policy was creating local economic growth and increasing capture fisheries production and guarantee the quality of capture fisheries.
\end{abstract}

Keywords : Fishery resources, sustainability, capture fisheries, minapolitan policy

\begin{abstract}
ABSTRAK
Sumberdaya Perikanan di Gorontalo Utara sangat besar. Potensi Manajemen Perikanan Daerah dari Laut Sulawesi ke Samudera Pasifik mencakup sekitar 590,970 ton ikan pelagis, termasuk 175.260 ton pelagis besar, 384,750 ton pelagis kecil dan jenis ikan lainnya sekitar 30,960 ton. Di sisi lain, pemanfaatan sumberdaya perikanan masih minimum hanya $46 \%$. Pemerintah Gorontalo Utara menetapkan perikanan tangkap sebagai program utama untuk meningkatkan kesejahteraan masyarakat untuk meminimalkan kurangnya pemanfaatan sumberdaya perikanan. Pemerintah harus menyadari situasi ini untuk merumuskan dan memutuskan setiap kebijakan. Kebijakan yang telah diterapkan di tahun terakhir di Gorontalo Utara adalah Minapolitan yang diselenggarakan oleh Departemen Kelautan dan Perikanan Indonesia bergabung dengan Pemerintah Daerah. Jadi, penelitian pengembangan penangkapan perikanan berdasarkan Model minapolitan diperlukan untuk merancang model kebijakan sebagai panduan untuk memutuskan kebijakan perikanan tangkap. Metodologi yang digunakan dalam penelitian ini adalah analisis produksi surplus untuk menganalisis sumber daya ikan yang tepat untuk menangkap ikan, dan analisis SEM (Struktur Equation Modeling). Hasil penelitian menunjukkan bahwa pemanfaatan sumber daya perikanan masih kurang di bawah MSY (Maximum Sustainable Yield). Beberapa program yang harus dikembangkan adalah purse seine, tuna hand line, bagan, garis tangan, dan payang. Tujuan dari kebijakan minapolitan adalah menciptakan pertumbuhan ekonomi lokal dan meningkatkan produksi perikanan penangkapan dan menjamin kualitas perikanan tangkap.
\end{abstract}

Kata kunci: Sumberdaya perikanan, keberlanjutan, penangkapan ikan, kebijakan minapolitan 


\section{PENDAHULUAN}

Sumber daya perikanan di Kabupaten Gorontalo Utara diperkirakan mempunyai potensi perikanan tangkap sebesar 590.970 ton yang terdiri dari ikan pelagis besar 175.260 ton, ikan pelagis kecil 384.750 ton, dan jenis ikan lainnya sebesar 30.960 ton. Diukur dari tingkat pemanfaatan diperkirakan baru mencapai $46 \%$ (Dinas Kelautan dan Perikanan Kabupaten Gorontalo Utara, 2010).

Rendahnya tingkat pemanfaataan sumberdaya perikanan tangkap di Kabupaten Gorontalo Utara, memberikan harapan bagi pemerintah untuk mengandalkan perikanan tangkap menjadi salah satu andalan pertumbuhan ekonomi di daerah, dan harapan tersebut perlu didukung oleh kebijakan-kebijakan pemerintah dalam pengembangkan perikanan tangkap. Pada tahun 2010 kebijakan pengembangan perikanan tangkap di Kabupaten Gorontalo Utara adalah kebijakan minapolitan yang merupakan salah satu pilot project program minapolitan di Indonesia. Harapan pemerintah melalui kebijakan minapolitan yaitu dapat mengoptimalkan pengelolaan sumberdaya ikan yang dimiliki oleh daerah, sehingga berdampak pada peningkatkan pendapatan masyarakat nelayan.

Permasalahan kebijakan adalah, apakah desain kebijakan program sesuai dengan kebutuhan masyarakat dan faktor-faktor yang mendukung tercapainya suatu kebijakan perikanan sudah sesuai?. Untuk itu, perlunya suatu kajian model pengembangan perikanan tangkap berbasis minapolitan yang menjadi salah satu acuan kebijakan pengembangan perikanan, khususnya perikanan tangkap.

Belum tercapainya peningkatan pendapatan nelayan, diakibatkan oleh rendahnya produksi hasil perikanan tangkap dan belum terjaminnya mutu hasil tangkapan sesuai yang diinginkan oleh konsumen. Dengan rendahnya produksi dan mutu hasil tangkapan akan berdampak pada terhambatnya pusat pertumbuhan ekonomi di wilayah kawasan minapolitan. Diduga ada faktorfaktor yang berpengaruh, sehingga kebijakan minapolitan perikanan tangkap belum sesuai dengan apa yang diharapkan oleh pemerintah.

Sesuai dengan konsep minapolitan yaitu pengembangan perikanan tangkap yang berbasis komoditi unggulan, maka perlu dukungan unit alat tangkap yang layak dikembangkan untuk menambah produksi dan menjamin mutu hasil tangkapan yang mendukung kebijakan minapolitan. Sehingga, diperlukan terobosan konsep yang dapat mendorong tercapainya kebijakan minapolitan di Kabupaten Gorontalo Utara.

Tujuan umum adalah menyusun model pengembangan perikanan tangkap berbasis minapolitan di Kabupaten Gorontalo Utara. Sedangkan tujuan khususnya adalah :

1) Menentukan potensi perikanan tangkap yang mendukung kelayakan usaha perikanan tangkap dalam menunjang kebijakan minapolitan perikanan tangkap,

2) Menentukan unit usaha perikanan tangkap yang sesuai dengan kebijakan minapolitan perikanan tangkap,

3) Menentukan faktor-faktor yang berpengaruh terhadap kebijakan minapolitan perikanan tangkap,

4) Mengembangkan model kebijakan perikanan tangkap berbasis minapolitan di Kabupaten Gorontalo Utara.

\section{METODOLOGI PENELITIAN}

Penelitian ini dilaksanakan selama 12 (dua belas) bulan, dimulai dari bulan Oktober 2010 sampai September 2011. Tahapan penelitian dimulai dari penyusunan rencana penelitian, orientasi lapangan, pengumpulan data, pengolahan data dan analisa data serta penyusunan disertasi. Lokasi penelitian dilaksanakan di Kabupaten Gorontalo Utara Provinsi Gorontalo.

\subsection{Metode Penelitian}

Metode yang digunakan dalam penelitian ini adalah metode survei lapangan dengan menggali data dan informasi langsung dari lokasi penelitian terhadap kebijakan minapolitan perikanan tangkap di Kabupaten Gorontalo Utara.

\subsection{Analisis}

Analisis yang dilakukan meliputi : analisis sumberdaya ikan, kelayakan 
investasi usaha perikanan tangkap dan SEM terhadap model pengembangan perikanan tangkap berbasis minapolitan.

\section{HASIL DAN PEMBAHASAN}

\subsection{Status perikanan}

Volume produksi terendah hasil tangkapan ikan adalah dari jenis ikan teri dengan jumlah 116 ton/tahun, Jenis ikan lain yang dianggap rendah terdiri dari jenis ikan kerapu, kuwe, kembung, selar, sardin, tuna, dan ikan tembang dengan jumlah hasil tangkapan dibawah 1.000 ton/tahun.

Penyebab kurangnya produksi hasil tangkapan ikan jenis teri, kerapu, kembung, selar, sardin, tuna dan tembang di Kabupaten Gorontalo Utara sejak tahun 2003 sampai 2010 di akibatkan oleh jumlah armada penangkapan yang masih kurang dan tidak mengalami peningkatan

Kurangnya produksi ikan, selain dipengaruhi oleh jumlah trip juga dipengaruhi oleh keadaan cuaca atau musim. Hal ini sesuai pendapat (Juwono, 1998) bahwa pengaruh musim akan berpengaruh terhadap kemampuan armada dan efektifitas alat tangkap dalam menangkap ikan yang diakibatkan oleh arus, angin kencang dan ombak yang besar. Di daerah Kabupaten Gorontalo Utara, musim barat merupakan musim yang kurang baik untuk melakukan kegiatan penangkapan ikan atau disebut musim paceklik.

Sedangkan untuk jenis ikan yang produksinya diatas seribu ton meliputi ikan layang, cakalang dan tongkol. Tingginya jumlah produksi tiga jenis ikan yang tertangkap tersebut, karena dipengaruhi oleh efektifnya alat tangkap dan alat bantu pengumpul ikan. Alat tangkap yang paling banyak menangkap tiga jenis ikan ini adalah alat tangkap purse seine dengan alat bantu rumpon.

\subsection{Produksi tertinggi ikan}

Hasil yang diperoleh dari estimasi merupakan jumlah tangkapan ikan maksimum yang diperbolehkan agar ketersediaan sumberdaya perikanan tangkap tetap lestari (berkelanjutan) atau MSY menunjukkan bahwa total potensi lestari sumberdaya perikanan tangkap di perairan Kabupaten Gorontalo Utara sejak tahun 2003 sampai tahun 2010, ikan layang produksi tertinggi 2.162ton/tahun dan batas MSY 2.845ton/tahun, ikan cakalang produksi tertinggi 3.357 ton/tahun dan batas MSY 3.562 ton/tahun, ikan tembang produksi tertinggi 807 ton/tahun dan batas MSY 1.130 ton/tahun, ikan teri produksi tertinggi 181 ton/tahun dan batas MSY 194 ton/tahun, ikan tuna produksi tertinggi 408 ton/tahun batas MSY 410ton/tahun, ikan sardin produksi tertinggi 531 ton/tahun dan batas MSY 579 ton/tahun, ikan selar produksi tertinggi 566 ton/tahun dan batas MSY 576 ton/tahun, ikan kembung 333ton/tahun dan batas MSY 415ton/tahun, ikan tongkol produksi tertinggi 1.694 ton/tahun dan batas MSY 1.729 ton/tahun, ikan kuwe produksi tertinggi 242 ton/tahun dan batas MSY 299 ton/tahun, ikan kerapu produksi tertinggi 691 ton/tahun dan batas MSY 749 ton/tahun. Berdasarkan hasil analisis bahwa sumberdaya yang dimanfaatkan masih dibawah batas MSY. Keadaan ini sesuai dengan kebijakan pemanfaatan sumberdaya perikanan berkelanjutan yang menganjurkan penangkapan ikan tidak lebih dari total MSY.

Pemanfaatan potensi perikanan tangkap yang dilakukan nelayan yang menggunakan alat tangkap bagan perahu, payang, pancing ulur, sero, bubu, dan gillnet untuk daerah penangkapan dibawah $4 \mathrm{mil}$, sementara alat tangkap pancing tegak atau pancing tuna dan purse seine diperuntukkan bagi daerah penangkapan ikan diatas 4 mil dari garis pantai dengan ukuran kapal minimum 5 GT.

\subsection{Kelayakan finansial}

Usaha perikanan purse seine mempunyai nilai NPV sebesar Rp. 241,082,370, pancing tuna Rp. 217,350,579, bagan perahu Rp 377,654,604, bubu Rp. 91,054,238, pancing ulur Rp. 142,830,012, payang Rp. 203,332,683, sero Rp. 35,151,021, dan gillnet Rp. 24,295,829. Hal ini, berarti nilai kas bersih pada saat yang akan datang lebih besar nilainya dari nilai investasi yang ditanamkan pada perikanan purse seine, bagan perahu, payang, pancing tuna, sero, pancing ulur, bubu, serta gillnet. net $\mathrm{B} / \mathrm{C}$ usaha perikanan tangkap semua unit alat tangkap menunjukan nilai positif. Dimana, unit usaha perikanan purse 
seine 1.56, pancing tuna 1.95, bagan perahu 4.17, bubu 10.11, pancing ulur 16.03, payang 5.84, sero 4.20, dan gillnet 2.74. Dan Nilai IRR dari perikanan purse seine sebesar $24.63 \%$, pancing tuna $32.50 \%$, bagan perahu $73.57 \%$, bubu $178.84 \%$, pancing ulur $283.79 \%$, payang $103.30 \%$, sero $73.96 \%$, dan gillnet $58.97 \%$. Dengan melihat hasil analisis NPV, IRR dan net B/C menunjukan bahwa dalam pengembangan usaha perikanan di Kabuapaten Gorontalo Utara layak untuk dilaksanakan.

\subsection{Keuntungan bersih}

Perhitungan ini adalah pendapatan bersih yang diperoleh setiap bulan dan tahun per unit usaha penangkapan ikan. Pendapatan bersih per unit usaha penangkapan di perairan Kabupaten Gorontalo Utara.

Pada tabel di bawah penerimaan berarti jumlah penghasilan yang diperoleh dari menjual produksi hasil tangkapan sesuai dengan kesepakatan dengan pembeli. Penghasilan bersih artinya pendapatan yang diterima nelayan setelah dipotong biaya produksi atau selisih antara penerimaan dengan biaya operasional melaut merupakan keuntungan (surplus) yang diterima nelayan.

\subsection{Model Pengembangan Perikanan Tangkap Berbasis Minapolitan}

Analsis SEM digunakan pada model pengembangan dilakukan dengan menggunakan pendekatan teroritis. Pendekatan teoritis dimaksudkan untuk mendapatkan justifikasi terhadap pengembangan perikanan tangkap berbasis minapolitan di Kabupaten Gorontalo Utara, sehingga model akhir yang diperoleh dapat dipertanggungjawabkan dan mendapat kebenaran secara ilmiah. Model dalam penelitian ini berusaha mengungkap bagaimanakah seharusnya pengembangan perikanan tangkap yang berbasis minapolitan seperti yang di jelaskan pada Gambar 1 dan 2.

Setelah dilakukan analisis dari model pengembangan perikanan berbasis minapolitan, maka dilakukan pengujian terhadap asumsi dasar SEM. Pengujian hipotesis uji kesesuaian model penelitian bahwa $\mathrm{H}_{0}$ : Matriks kovariansi data sampel tidak berbeda dengan maktriks populasi yang diestimasi. Dengan kriteria uji: $\mathrm{H}_{0}$ diterima, jika nila $p$ hitung $\geq 0,05$; RMSEA $\leq 0,08$ dan CFI $\geq$ 0,90 .

Gambar 1 menunjukan nilai $p$ hitung $=0.00<0,05$, nilai Root Mean Fit Indeks of Approximation (RMSEA) $=0,054$ $<0,08$, dan nilai Comparative Fit Indeks $(\mathrm{CFI})=0,71<0,90$. Maka $\mathrm{H}_{1}$ diterima atau $\mathrm{H}_{0}$ ditolak, artinya model yang di uji tidak mampu mengestimasi matriks kovariansi populasi atau hasil estimasi parameter model tidak dapat diberlakukan pada populasi penelitian. Dengan demikian hasil pengujian kesesuian model pengembangan perikanan tangkap berbasis minapolitan menunjukan model pengukuran tidak fit dengan data, maka model perlu diperbaiki. Langkah berikutnya adalah melakukan modifikasi terhadap model yang tidak memenuhi syarat pengujian yang telah dilakukan seperti yang terlihat pada Gambar 2.

Gambar 2 menunjukan nilai $p$ hitung $=1.00>0.05$, nilai Root Mean Square Error Appoximation (RMSEA) $=0.0$ $<0.08$ dan nilai Comparative Fit Indeks $(\mathrm{CFI})=1.00>0.90$. Berdasarkan hasil uji model tersebut, maka $\mathrm{H}_{0}$ diterima atau $\mathrm{H}_{1}$ ditolak, artinya model yang diuji mampu mengestimasi matriks kovariansi populasi atau hasil estimasi parameter model dapat diberlakukan pada penelitian. Dengan demikian bahwa hasil pengujian kesesuaian model menunjukan bahwa model pengukuran fit dengan data atau model pengembangan perikanan tangkap berbasis minapolitan sesuai dengan pengujian.

Hasil analisis SEM terhadap model pengembangan perikanan tangkap berbasis minapolitan di Kabupaten Gorontalo Utara menunjukan adanya pengaruh langsung terhadap sumberdaya ikan, alat tangkap, sarana dan prasarana, aspek sosial nelayan, keamanan dan kepastian hukum serta pengawasan, dan aspek ekonomi terhadap kebijakan minapolitan perikanan tangkap. 
Tabel 1. Pendapatan bersih usaha perikanan tangkap di Kabupaten Gorontalo Utara

\begin{tabular}{|c|l|l|l|}
\hline No. & Jenis Usaha & $\begin{array}{c}\text { Pendapatan } \\
\text { Pertahun }\end{array}$ & $\begin{array}{c}\text { Pendapatan } \\
\text { Perbulan }\end{array}$ \\
\hline 1 & Purse sene & Rp. 69.120,000 & Rp. 5,760,o00 \\
2 & Pancing Tuna & Rp. 49.410,000 & Rp. 4,117,500 \\
3 & Bagan Perahu & Rp. 43,950,000 & Rp. 3,662,500 \\
4 & Bubu & Rp. 14,163,750 & Rp. 1,180,313 \\
5 & Pancing Ulur & Rp. 13,730,000 & Rp. 1,144,167 \\
6 & Payang & Rp. 26,710,000 & Rp. 2,225,833 \\
7 & Sero & Rp. 13,168,000 & Rp. 1,097,333 \\
8 & Gillnet & Rp. 13,380,000 & Rp. 1,115,000 \\
\hline
\end{tabular}

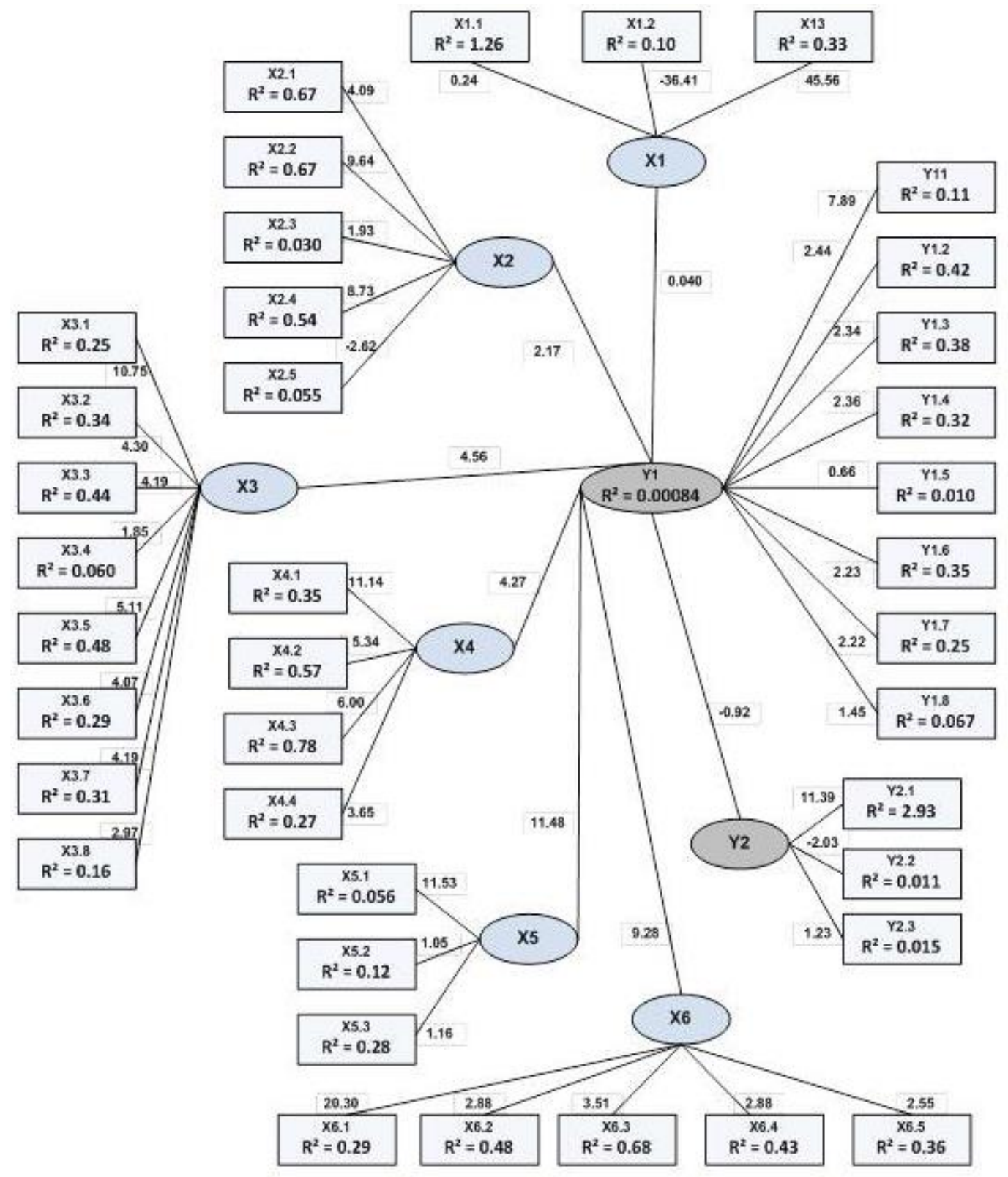

Chi Square $=893.90$, df $=695$, P-value $=0.00$, RMSEA $=0.054, \quad$ CFI $=0.71$

Gambar 1. Estimasi model pengembangan perikanan tangkap berbasis minapolitan di Kabupaten Gorontalo Utara 
Keterangan Gambar 1 :

$\mathrm{X}_{1} \quad=$ Sumberdaya ikan,

$\left(\mathrm{X}_{1.1}\right)=$ Musim,

$\left(\mathrm{X}_{1.2}\right)=$ Jarak antara daerah fishing ground dan fishing base,

$\left(\mathrm{X}_{1.3}=\right.$ Zona penangkapan ikan,

$\mathrm{X}_{2} \quad=$ Alat tangkap,

$\left(\mathrm{X}_{2.1}\right)=$ Efektifitas menangkap ikan,

$\left(\mathrm{X}_{2.2}\right)$ = Pengoperasian alat tangkap,

$\left(\mathrm{X}_{2.3}\right)=$ Perbaikan alat tangkap,

$\left(\mathrm{X}_{2.4}\right)=$ Ramah lingkungan,

$\left(\mathrm{X}_{2.5}\right)=$ Keamanan hasil tangkapan,

$\mathrm{X}_{3}=$ Sarana dan prasarana,

$\left(\mathrm{X}_{3.1}\right)=$ TPI dan pelabuhan perikanan,

$\left(\mathrm{X}_{3.2}\right)=\mathrm{Es}$,

$\left(\mathrm{X}_{3.3}\right)=$ Tempat penampungan ikan,

$\left(\mathrm{X}_{6.1}\right)=$ Pasar,

$\left(\mathrm{X}_{6.2}\right)=$ Kemitraan,

$\left(\mathrm{X}_{6.3}\right)$ = Dukungan modal,

$\left(\mathrm{X}_{6.4}\right)=$ Kestabilan harga Ikan,

$\left(\mathrm{X}_{6.5}\right)=$ Kemudahan perizinan,

$\left(\mathrm{Y}_{1}\right)=$ Kebijakan minapolitan perikanan tangkap,

$\left(\mathrm{Y}_{1.1}\right)=$ Purse seine,

$\left(\mathrm{Y}_{1.2}\right)$ = Pancing ikan tuna,

$\left(\mathrm{Y}_{1.3}\right)=$ Bagan perahu,

$\left(\mathrm{Y}_{1.4}\right)$ = Bubu,

Hasil analisis SEM model yang fit pada pengujian model pengembangan perikanan tangkap berbasis minapolitan di Kabupaten Gorontalo Utara bahwa; (1). musim dan zona penangkapan berpengaruh terhadap sumberdaya ikan, (2). efektifitas menangkap ikan, pengoperasian alat tangkap, ramah lingkungan berpengaruh terhadap alat tangkap, (3). TPI dan pelabuhan perikanan, kesediaan es, tempat menampung ikan, tempat pengolah ikan, dan kesediaan BBM terhadap sarana dan prasarana, (4.) tingkat kepercayaan nelayan, kemampuan berkelompok atau berorganisasi, kecintaan terhadap pekerjaan, dan penyerapan tenaga kerja dibidang perikanan tangkap berpengaruh terhadap aspek sosial nelayan, (5). kepastian hukum, keamanan, dan pengawasan berpengaruh terhadap faktor keamanan, hukum dan pengawasan, (6). pasar, kemitraan, dukungan modal, dan kestabilan harga ikan merupakan faktor yang berpengaruh pada aspek ekonomi, (7). usaha perikanan purse seine, pancing tuna, bagan perahu, pancing ulur, dan payang berpengaruh terhadap kebijakan minapolitan perikanan tangkap, (8) menciptakan pertumbuhan ekonomi, peningkatan produksi hasil tangkapan,
$\left(\mathrm{X}_{3.4}\right)=$ Sarana informasi,

$\left(\mathrm{X}_{3.5)}=\right.$ Tempat pengolah ikan,

$\left(\mathrm{X}_{3.6}\right)$ = Bengkel,

$\left(\mathrm{X}_{3.7}\right)=\mathrm{BBM}$

$\left(\mathrm{X}_{3.8}\right)$ = Kedai nelayan,

$\mathrm{X}_{4} \quad=$ Aspek sosial nelayan,

$\left(\mathrm{X}_{4.1}\right)=$ Tingkat kepercayaan,

$\left(\mathrm{X}_{4.2}\right)=$ Kemampuan berkelompok $/$ berorganisasi,

$\left(\mathrm{X}_{4.3}\right)=$ Kecintaan terhadap pekerjaan,

$\left(\mathrm{X}_{4.4}\right)=$ Tenaga kerja,

$\mathrm{X}_{5} \quad=$ Keamanan, kepastian hukum dan pengawasan,

$\left(\mathrm{X}_{5.1}\right)=$ Kepastian hukum,

$\left(\mathrm{X}_{5.2}\right)$ = Keamanan,

$\left(\mathrm{X}_{5.3}\right)$ = Pengawasan,

$\mathrm{X}_{6} \quad=$ Aspek ekonomi,

$\left(\mathrm{Y}_{1.5}\right)=$ Pancing ulur,

$\left(Y_{1.6}\right)$ = Payang,

$\left(\mathrm{Y}_{1.7}\right)=$ Sero,

$\left(\mathrm{Y}_{1.8}\right)=$ Gillnet

$\mathrm{Y}_{2}=$ Sasaran minapolitan,

$\left(\mathrm{Y}_{2.1}\right)=$ Menciptakan pertumbuhan ekonomi di daerah,

$\left(\mathrm{Y}_{2.2}\right)=$ Peningkatan produksi hasil tangkapan,

$\left(\mathrm{Y}_{2.3}\right)=$ Menjamin mutu hasil tangkapan,

dan menjamin mutu hasil tangkapan berpengaruh terhadap sasaran minapolitan.

Faktor-faktor yang tidak berpengaruh terhadap model pengembangan perikanan tangkap berbasis minapolitan yaitu: (1). jarak antara daerah fishing ground dan fishing base tidak berpengaruh terhadap sumberdaya ikan, (2). perbaikan alat tangkap dan keamanan hasil tangkapan tidak berpengaruh terhadap alat tangkap, (3). sarana informasi, bengkel dan kedai nelayan tidak berpengaruh terhadap sarana dan prasarana, (4). kemudahan perizinan tidak berpengaruh terhadap aspek ekonomi, (5). usaha perikanan bubu, sero dan gillnet tidak berpengaruh terhadap kebijakan minapolitan perikanan tangkap.

Pengembangan perikanan tangkap berbasis minapolitan di Kabupaten Gorontalo Utara yang layak dikelola adalah ikan layang, cakalang, tembang, teri, tuna, sardin, selar, kembung, tongkol, kuwe, dan kerapu masih bisa di kembangkan. Hal ini sesuai dengan hasil analisis MSY menunjukan bahwa sumberdaya ikan tersebut belum mengalami overfishing. 


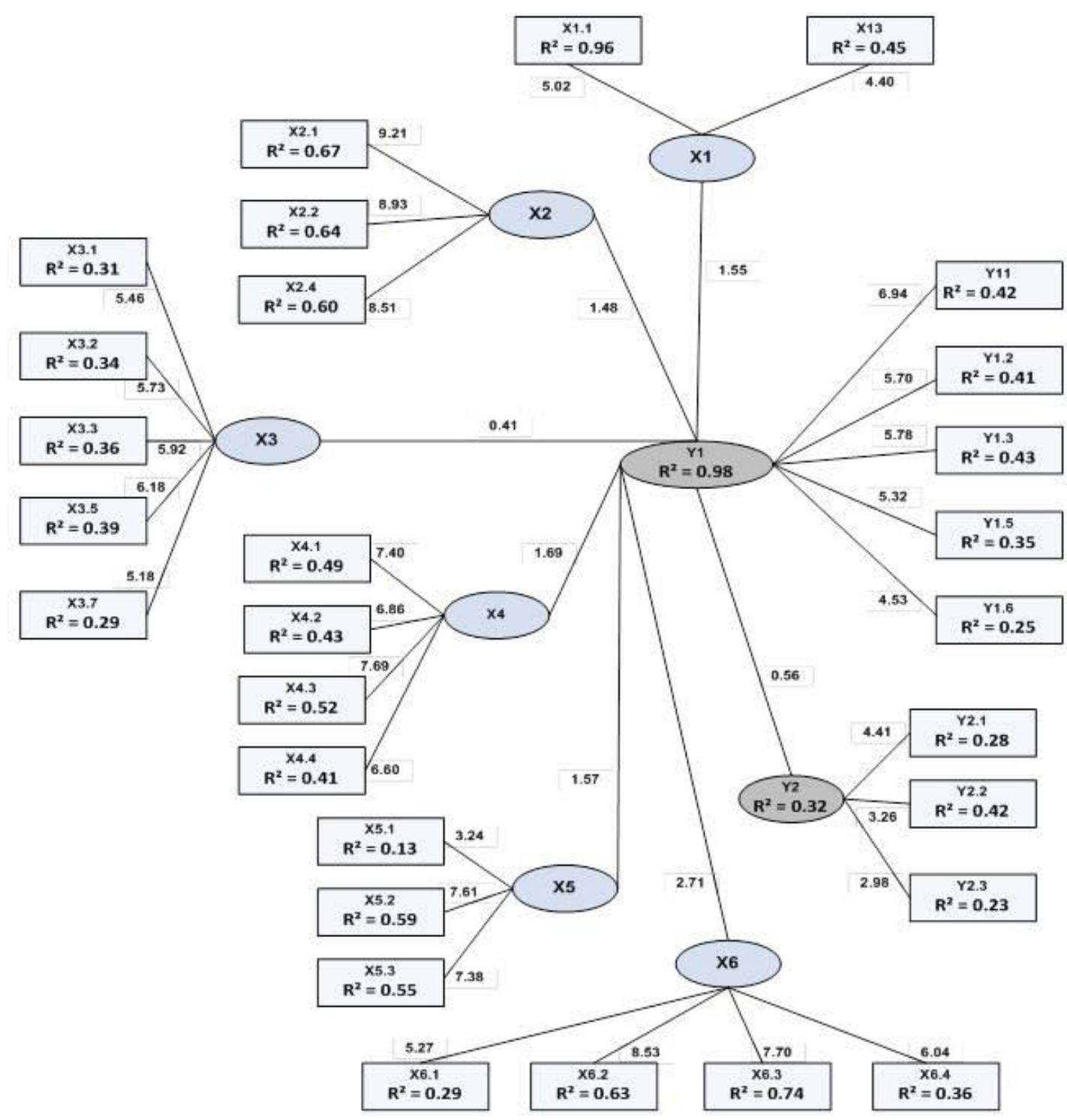

Chi Square $=285.84, \quad$ df $=355, P$-value $=1.00$, RMSEA $=0.0, \quad C F I=1.00$

Gambar 2. Estimasi model fit pengembangan perikanan tangkap berbasis minapolitan di Kabupaten Gorontalo Utara

Dalam pengembangan perikanan kedepan, maka salah satu langkah yang perlu dilakukan adalah peningkatan usaha perikanan tangkap yang produktif dalam menujang kebijakan minapolitan perikanan tangkap yaitu purse seine, pancing tuna, bagan perahu, pancing ulur dan payang. Pada saat yang sama perlu pengawasan agar kegiatan penangkapan tetap mempertimbangkan potensi lestarinya.

Zona penangkapan atau pembagian daerah penangkapan yang sesuai dengan ukuran kapal dan jenis alat tangkap yang digunakan, perlunya pengaturan operasi penangkapan ikan dilapangan, dimaksudkan agar tidak terjadi benturan antara kelompok nelayan, baik antar nelayan tradisional maupun dengan pemilik kapal besar. Dalam hal ini perlunya peraturan yang harus dipatuhi dan penindakan hukum yang tegas untuk menjaga kelestarian sumberdaya ikan.

Penyediaan infrastruktur di wilayah menjadi faktor pendukung dalam pengembangan perikanan tangkap yang berbasis minapolitan. Infrastruktur wilayah antara lain penyediaan pabrik es, gedung cold storage, tempat pengolah ikan, dan tersedianya BBM. Dalam hal ini, diperlukan kebijakan pemerintah, baik pusat maupun daerah yang sinergis 
dan harmonis dalam pengembangan infrastruktur wilayah tersebut. Kerjasama adalah adanya keterkaitan dan jalinan kemitraan yang didasarkan pada asas saling membutuhkan, saling memperkuat dan saling menguntungkan. Faktor ini diarahkan untuk terwujudnya kerjasama yang integratif, strategis, sinergis, inovatif dan berkelanjutan. Dalam hal ini, kemitraan dapat dilakukan pada aspek pemasok bahan yang dibutuhkan dalam kegiatan perikanan tangkap, penyediaan modal, terbukanya akses pasar dan jaminan harga yang ditimbulkan oleh adanya kerjasama.

Ada hal yang perlu dipikirkan dalam pengembangan perikanan tangkap yaitu pertama menjamin mutu ikan dan peningkatan produksi oleh nelayan yang dengan sendirinya mendatangkan investor atau pemodal, kedua peran pemerintah baik pemerintah pusat dan daerah memiliki peran menciptakan dan menjaga hubungan bisnis antara nelayan dengan pengusaha atau pemilik modal yang datang.

Mutu kebijakan sangat dipengaruhi oleh kualitas penyelenggaraan pemerintah untuk menciptakan iklim (lingkungan) yang kondusif. Kebijakan akan pengembangan perikanan tangkap berbasis minapolitan harus diarahkan untuk mendorong pengembangan kegiatan-kegiatan perikanan tangkap, baik pada tingkat nelayan maupun pihak swasta. Sedangkan penyelenggara pemerintahan harus memiliki kemampuan pelayanan yang baik kepada pelaku usaha, misal kemudahan berinvestasi, kemudahan perizinan, kemudahan pemasaran produk, penyediaan fasilitas-fasilitas pendukung kegiatan usaha perikanan tangkap, penghapusan pungutan ilegal, dan jaminan keamanan. Dengan demikian, mutu kebijakan dan penyelenggaraan pemerintah yang baik memerlukan kerjasama, sinkronisasi dan koordinasi pihak terkait.

\section{KESIMPULAN DAN SARAN}

\subsection{Kesimpulan}

Pengembangan perikanan tangkap berbasis minapolitan di Kabupaten Gorontalo Utara layak dikembangkan. Hal ini, karena didukung oleh sumberdaya perikanan yang masih bisa dikembangkan dan pemanfaatan saat ini masih dibawah MSY. Jenis ikan tersebut meliputi ikan layang, cakalang, tembang, tuna, teri sardin, selar, kembung, tongkol, kuwe, dan ikan kerapu.

Unit usaha perikanan tangkap saat ini masih layak di kembangkan untuk mengelola sumberdaya perikanan yaitu perikanan purse seine, pancing tuna, bagan perahu, bubu, pancing ulur, payang sero, dan gillnet.. Kelayakan usaha ini didasarkan pada hasil analisis $\mathrm{NPV} \geq 0$, IRR $\geq$ tingkat suku bunga yang berlaku dan net $\mathrm{B} / \mathrm{C} \geq 1$. Nilai NPV.

Model pengembangan perikanan tangkap ikan berbasis minapolitan yaitu perikanan purse seine, pancing tuna, bagan perahu, pancing ulur dan payang. Dengan mempertimbangkan aspek sumberdaya perikanan, alat tangkap, sarana dan prasarana, aspek sosial, aspek ekonomi, mempertimbangkan keamanan, kepastian hukum dan pengawasan. Faktor-faktor tersebut untuk mencapai sasaran pengembangan perikanan tangkap berbasis minapolitan yaitu menciptakan pertumbuhan ekonomi di daerah, meningkatkan produksi hasil tangkapan dan menjamin mutu hasil tangkapan.

\subsection{Saran}

Dari hasil penelitian terhadap analisis model pengembangan perikanan tangkap berbasis minapolitan di sarankan perlu analisis lanjutan tentang berapa jumlah usaha perikanan tangkap yang akan dikembangkan?.

\section{DAFTAR PUSTAKA}

Adrianto, L. dan Tridoyo Kusumastanto, 2004. Penyusunan Rencana Pengelolaan Perikanan (Fisheries Management Plan) dan Rencana Pengelolaan Kawasan Pesisir (Coastal Management Plan). Makalah pada Training of Trainer (TOT) Marginal Fishing Community Development Pilot. Bappenas. Cipayung, 8 Oktober 2004. 42 hal.

Dinas Kelautan dan Perikanan, 2010. Laporan Tahunan. Gorontalo: Dinas Kelautan dan Perikanan Kabupaten Gorontalo Utara. 51 hal.

Gulland, J.A. 1983. Fish Stock Assessment. A Manual of Basic Methods. A wiley Publication. 223 p. 
Monintja D. 2001. Pemanfaatan Sumberdaya Pesisir dalam Bidang Perikanan Tangkap. Prosiding Pelatihan Pengelolaan Wilayah Pesisir Terpadu. Pusat Kajian Sumberdaya Pesisir dan Lautan.Institut Pertanian Bogor. Bogor. 156 hal.

Kementerian Kelautan dan Perikanan, (2010). Tentang Kebijakan Minapolitan http//cetak.kompas. $\mathrm{com} / \mathrm{red} / \mathrm{xml} / 2010 / 04 / 16 / 053035$ 17/.agar.ambisi.terwujud (Jumat, 16 April 2010).

Kesteven, G.L. 1973. Manual of Fisheries Science.Part 1 - An Introduction to Fisheries Science.FAO Fisheries Technical Paper No. 118. Food and Agriculture Organization of The United Nations, Rome.
Kusnendi, 2008. Model-model Persamaan Struktural. Satu dan Multigroup Sampel dengan LISREL. Bandung: Alfabeta.

Schaefer, M. 1954. Some Aspects of the Dynamics of Populations Important to the Management of Commercial Marine Fisheries. Bull. Inter-Am. Tropical Tuna Commission. 1 :2756.

Suseno, 2004. Analisis Kebijakan Pengelolaan Sumberdaya Perikanan Tangkap Disertasi Program Doktor. Sekolah Pascasarjana Institut Pertanian Bogor. Bogor. 221 hal.

Sutojo, S. 1995. Studi Kelayakan Proyek. Teori dan Praktek Seri Manajemen No.66. PT. Pustaka Binaman Pressindo, Jakarta. 165 hal. 